\title{
Enhancing Student Learning Through Hypermedia Courseware and Incorporation of Student Learning Styles
}

\author{
Curtis A. Carver, Jr., Richard A. Howard, and William D. Lane, SM
}

\begin{abstract}
This paper outlines attempts to enhance student learning by addressing different learning styles through course hypermedia. Students learn by a variety of different learning styles. Previously, instructors were unable to effectively address these different learning styles outside the classroom. Students were limited to paper-based course materials that presented information primarily in a sequential manner according to the author's perception of the organization of the material. While this addressed the needs of some students, others did not prepare effectively because the presentation differed significantly from the student's preferred learning style. Two approaches were developed to address this problem. The first approach was the development of hypermedia courseware. This provided a wide variety of tools which students could use to prepare for lessons. In this way students retained complete control over how they prepared for a lesson and could choose those hypermedia tools that were most conducive to their learning. An assessment of the multimedia and hypertext documents in the course revealed that the value of a particular multimedia tool to a student varied widely. Each student was traversing the course material according to his/her unique learning style. Unfortunately, the plethora of tools confused some students because they were uncomfortable making active choices of what course material would be most conducive to their learning. As a result, a second approach was adopted. An adaptive hypermedia interface was developed that provided dynamic tailoring of the presentation of course material based on the individual student's learning style. By tailoring the presentation of material to the student's learning style, the authors believe students learned more efficiently and more effectively.
\end{abstract}

Index Terms-Hypermedia, learning styles, multimedia.

\section{INTRODUCTION}

$\mathbf{T}$ THIS paper outlines attempts to enhance student learning by addressing different learning styles through hypermedia courseware. Students learn through a variety of different learning styles. Previously, instructors were unable to effectively address these different learning styles outside the classroom. Students were limited to paper-based course materials that presented material primarily in a sequential manner according to the author's perception of the organization of the material. While this addressed the needs of some students, many others could not prepare effectively and efficiently because the presentation of course material differed significantly from the student's preferred learning style.

Manuscript received August 29, 1996; revised November 2, 1998. The authors are with the Department of Electrical Engineering and Computer Science, United States Military Academy, West Point, NY 10996 USA. Publisher Item Identifier S 0018-9359(99)01245-5.

\begin{tabular}{|c|c|c|c|}
\hline Definitions & \multicolumn{2}{|c|}{ Dimensions } & Definitions \\
\hline Do it & Active & Reflective & $\begin{array}{c}\text { Think about } \\
\text { it }\end{array}$ \\
\hline $\begin{array}{c}\text { Learn } \\
\text { Facts }\end{array}$ & Sensing & Intuitive & $\begin{array}{c}\text { Learn Con- } \\
\text { cepts }\end{array}$ \\
\hline $\begin{array}{c}\text { Require } \\
\text { Pictures }\end{array}$ & Visual & Verbal & $\begin{array}{c}\text { Require } \\
\text { Reading or } \\
\text { Lecture }\end{array}$ \\
\hline $\begin{array}{c}\text { Infer Prin- } \\
\text { ciples from } \\
\text { Facts }\end{array}$ & Inductive & Deductive & $\begin{array}{c}\text { Deduce out- } \\
\text { comes from } \\
\text { principles }\end{array}$ \\
\hline $\begin{array}{c}\text { Step lyy } \\
\text { Step }\end{array}$ & Sequential & Global & Big Picture \\
\hline
\end{tabular}

Fig. 1. Felder's learning dimensions.

To address this problem, a series of hypertext, multimedia, and hypermedia tools were developed as the basis for enhancing the course, CS383, Computer Systems [1]-[3]. These tools provided a rich selection of World Wide Web (WWW) hypermedia-based tools. The enhancements to the course were enthusiastically received by students and significantly improved the performance of many students. The increased student control and flexibility in deciding how and when they studied transformed many students from passive to active participants in the learning process.

Unfortunately, it also confused some students as they were unsure as to how to proceed through the plethora of course materials. Anecdotal evidence based on student surveys over three semesters suggested that approximately $25 \%$ of the students remained confused and uncertain at the end of the semester as to how to effectively use the hypermedia material [4]. This wasted student time and required a different approach than simply presenting course material to students.

From this response it was clear that a mechanism for tailoring the presentation of the course material was needed. By tailoring lesson presentation to the individual student, students could learn more in less time because the students could absorb the material more rapidly and were more receptive to how the material was presented. As a result, an adaptive hypermedia approach using student learning styles was developed.

\section{Previous EFforts}

Adaptive hypermedia interfaces have been discussed previously in several papers [5]-[11]. These papers focused on dynamically assembling information and presenting that 


\begin{tabular}{|c|c|c|c|c|c|c|}
\hline & Lsn Objectives & Slide shows & Hypertext & Response System & Digital Library & Media Clips \\
\hline Global & $\sqrt{ }$ & & $\sqrt{ }$ & $\sqrt{ }$ & $\sqrt{ }$ & $\sqrt{ }$ \\
\hline Sequential & & $\sqrt{ }$ & $\sqrt{ }$ & & & $\sqrt{ }$ \\
\hline Verbal & $\sqrt{ }$ & $\sqrt{ }$ & $\sqrt{ }$ & & $\sqrt{ }$ & $\sqrt{ }$ \\
\hline Visual & & $\sqrt{ }$ & & & $\sqrt{ }$ & $\sqrt{1}$ \\
\hline Active & & $\sqrt{ }$ & $\sqrt{ }$ & $\sqrt{ }$ & & \\
\hline Reflective & $\sqrt{ }$ & $\sqrt{ }$ & $\sqrt{ }$ & $\sqrt{ }$ & $\sqrt{ }$ & $\sqrt{ }$ \\
\hline Sensing & & $\sqrt{ }$ & $\sqrt{ }$ & $\sqrt{ }$ & $\sqrt{ }$ & $\sqrt{ }$ \\
\hline Intuitive & $\sqrt{ }$ & $\sqrt{ }$ & & $\sqrt{ }$ & & $\sqrt{ }$ \\
\hline
\end{tabular}

Fig. 2. Summary of learning styles and hypermedia course components.

information according to the user's class and knowledge state. No attempt was made to incorporate the student's learning style into the decision of what information to present to the student. Similarly, Felder's learning styles suggest a methodology for classroom presentation but have not been adapted for hypermedia-based courseware [12]-[14]. Felder's learning styles have been incorporated into multimedia courseware in only one instance [15], [16]. Yet this multimedia courseware was more than two orders of magnitude smaller than the CS383 computer systems hypermedia courseware and was not adaptive. To date, no system coupling Felder's learning styles with adaptive hypermedia to provide tailored lesson presentations has been proposed. In this regard, the work presented here is both novel and significantly different from previous efforts in this field.

\section{FELDER's LEARNING MODEL}

Selection of a learning style model is key to the development of a hypermedia course that addresses different learning styles. While several models are currently being used such as the Kolb/McCarthy model [17], [18] and the Myers-Briggs Type Inventory [19], the authors believe that the Felder Model is most appropriate for hypermedia courseware. Felder's Learning Model categorizes an individual's preferred learning style along a sliding scale of five dimensions as shown in Fig. 1 [14]. While these preferences are dynamic on a daily basis, in general an individual can be categorized with a preferred learning style in each dimension.

\section{The Hypermedia COURSE}

Hypermedia CS383 provides a vast array of media elements to support the transfer of information. The hypermedia course provides: 143 audio files, 63 graphic files, 57 digital movies, instructor slideshows for every lesson, lesson objectives, notetaking guides, a student legacy system with over 471 student papers and slideshows from previous semesters, and 300 pages of course hypertext with 178 cross references, 678 terms with pop-up definitions, and 600 terms that students can search. These hypermedia resources were primarily used outside of the classroom to facilitate student preparation and lesson review. A wide variety of tools were developed to address the different learning styles of our students and provide them with real choices in preparing for a lesson.

Each hypermedia course element supports one or more of Felder's learning dimensions. However, regardless of which hypermedia lesson component is chosen, all components support both active and reflective learners. Instead of passively accepting the information presented, the hypermedia course forces students to constantly make choices. This facilitates active learners who become energetically involved in the learning process. Reflective learners are likewise facilitated by the computer-based nature of the material. Students can stop and reflect at any point during their studies and ponder the meaning of the material presented. The other learning styles are supported to varying degrees by the different hypermedia lesson components as reflected in Fig. 2. Subsequent sections explore each hypermedia course component and the student learning styles supported.

Clicking on the lesson objective icon on the course web page takes the student to the lesson objectives for each lesson. If the student selects this option at the main menu, all of the course lesson objectives are presented. If the student selects this option at the lesson level, only the objectives for that lesson are presented. These provide an overview of what the instructor feels is important in the lesson and allows the student to focus on key concepts. Most students begin their study by reviewing these objectives.

Lesson objectives particularly address global, verbal, and intuitive learners. Global learners appreciate the lesson overview before the details are presented. Students can also scan the objectives of different lessons or the entire course and determine the "big picture." Lesson objectives provide global learners with this information and a means of easily jumping between different lessons so that the connection between the different lessons will be clear.

Lesson objectives also address verbal learners. Verbal learners prefer words, either oral or written, as their preferred method of learning. Lesson objectives facilitate a textual overview of the course material. Finally, intuitive learners respond to concepts and the lesson objectives detail the main concepts of the course. Without the clutter of detailing facts, intuitive learners can rapidly explore the main ideas in a course and how they are related.

Each lesson slideshow is structured around the learning objectives. The slideshow consists of a series of lesson objectives separated by their supporting slides. This provides the overall lesson structure and helps to keep the student focused on the lesson objectives at hand. Overall, there are approximately 600 slides in 25 lessons. Three flavors of the slideshow were prepared: text, basic slideshow, and full multimedia. 
These slideshows facilitate verbal, visual, sequential, sensing, and intuitive learners. Verbal learners like the text version of the slideshows so that they can read the slideshows. Visual learners prefer the public domain and full multimedia versions of the slideshows. Sequential learners like the structure of the slideshows where each lesson objective is supported by slides so that the objectives can be sequentially explored. Intuitive learners favor the concepts covered through slideshows and the open-ended nature of the slideshows while the sensing learners like all of the embedded media elements and facts contained therein that directly address their sensing needs. With the exception of the global learners, the electronic slideshows provide an excellent tool for student preparation outside the classroom.

Course reading assignments [20], [21] were supplemented with a hypertext file covering each lesson's material. The hypertext file was based on the Windows Help engine and was developed using Doc-to-Help 1.6. These products were used due to the widespread use of Microsoft Windows by Academy cadets and the ease of use and low cost for Doc-to-Help. The hypertext features 678 terms with pop-up definitions, 700 index terms, and 178 cross references in a 300-page hypertext document.

The course hypertext supports sequential, global, sensing, and verbal learners. Sequential learners benefit from the hierarchical structure of the hypertext that allows them to sequentially explore the course material in detail. Global learners prefer the search capabilities of the hypertext which allows them to jump to various topics, explore topics of interest, and build their own cognitive map of the course material. Sensing learners like the factual nature of the material covered in the hypertext. Finally, verbal learners prefer to learn via words and the hypertext is over 300 pages of detailed text. In fact, despite the fact that course instructors primarily present information using the multimedia slideshows, some verbal learners never use the slideshows and instead follow the class presentation using the course hypertext.

After the students prepare for a lesson using the hypermedia tools, they can assess their understanding of the course material using the student response system. The student response system provides automated grading of questions in real time that are posed to the user as a set of Common Gateway Interface (CGI) forms. Students get feedback on the correct answer, the relevant lesson objective, and how the question relates to Bloom's Taxonomy [22]. They can take the assessments as often as they wish since the assessments are graded for participation only. The professor obtains feedback on individual and section performance. Professors can then tailor lesson presentations to those lesson objectives that are causing the students the most difficulty.

The student response system facilitates active, global, sensing, and intuitive learners. Active learners enjoy making choices and exploring the course material via their choices. Since most of the exam questions require the synthesis of multiple learning objectives, the student response system is an ideal learning component for global students to learn course information. Furthermore, the student response system supports: open-ended, short answer, concept questions and factual, true/false or multiple choice type questions. Depending on the type of question, both intuitive and sensing learners are addressed. Finally, learning styles are irrelevant if the student does not prepare for class regularly. By facilitating automatic grading of homework assignments on a nightly basis, the student response system supports the most important student learning style-studying.

In addition to other grading requirements for a computer systems course, students are required to make two oral presentations and submit three papers. To minimize student difficulty understanding the requirements and to improve the quality of work submitted by students, a Course Digital Library was developed that has more than 450 student papers and/or electronic slideshows from previous semesters.

Student slideshows and written papers facilitate verbal, visual, sensing, and global learners. Verbal learners like the written papers as a means of learning while the visual learners prefer the slideshows. Global learners like the ability to explore informational resources indirectly related to the course material as a means of organizing the material and how it all fits together. Student papers and presentations must be persuasive and convince the reader of the best option among a variety of choices. These submissions are often very factual with little conceptual information covered. Sensing learners like the factual basis of the student submissions that are uncluttered with conceptual discussions. All of the students like to see the efforts of previous students as it enhances communications between the instructor and the students. Armed with concrete examples of student submissions and instructor grading tendencies, the course digital library improves student submissions.

HTML allows for the easy incorporation of media clips into lesson pages that enhance student understanding by utilizing different senses. The sound files allow the instructor to emphasize key points or areas that require clarification so that the student does not make a common mistake. The graphics display the concepts being discussed and allow the student to associate an image with a concept. Finally, the videos allow the instructor to illustrate key points and to show a sequence of events as they occur. Although these videos are large files, they are key to illustrating concepts that can be readily lost in a sea of words.

The audio, graphic, and video files support verbal, visual, global, sequential, sensing and intuitive learners. The media tools are effective for different learners because they are tools that can be wielded to complement different learning styles. Verbal learners like the sound files. Visual learners like the digital movies and graphics. Global, sequential, and intuitive learners like the digital movies depending on how the material is presented. Sensing learners are affected directly and revel in all the media tools since these tools convey primarily factual information, not concepts, through the senses.

\section{OTHER HyPERMEDIA TOOLS}

\section{A. CS383 Virtual Computer}

The CS383 virtual computer allows students to construct a virtual computer and run a series of different benchmarks 
against their virtual computer. Students construct a virtual computer by clicking on the different components that they wish to configure and selecting from the options presented in drop-down boxes. Currently fourteen components of the computer can be configured. The students then select one of five different benchmarks and click on the Go! button. As the benchmark is running, the student views an animation with the components of the computer that are being most heavily utilized. After the benchmark runs, the student receives feedback as to what the dominant bottleneck in the computer system was and how to fix it.

The CS383 virtual computer facilitates global, visual, and verbal learners. Students can explore the internal workings of a computer by building one and testing it. Global students benefit the most by having the ability to quickly vary system parameters and see the impact on the overall system. The interrelationships between various computer components can be explored and different strategies for building a computer investigated. Visual learners are attracted to the interface into the virtual computer and the video segments. Verbal learners prefer the HTML text.

\section{B. CS383 DOOM Scenario}

The CS383 DOOM Scenario allows students to take quizzes in a DOOM gaming environment. DOOM is a pseudo threedimensional commercial gaming engine that is extremely popular among computer gamers. It features a fast, realtime gaming environment. The purpose of DOOM is for the player to complete a scenario involving the recent invasion of demonic aliens from another dimension. The player, armed initially with only a pistol, rapidly explores a series of rooms to find the exit to the next level. Aliens encountered along the way attack the player.

DOOM is used as the basis for a cooperative in-class and out-of-class exercise. Working in an out-of-class group of three or four, students complete an 80-question multiple choice exercise. In class, the groups check their answers in a graded DOOM scenario. There are 20 rooms per level and five levels corresponding to processors, motherboards, storage systems, graphics systems, and as a bonus, the Department of Electrical Engineering and Computer Science. Each question becomes a room with four doors representing four possible answers. Incorrect answers result in confrontations with monsters while correct answers result in additional ammunition and medical kits.

Due to student interest in the game and their grade, there is often a lively debate among the group members concerning which door to open and why one answer is better than another. To minimize game playing ability, students are allowed to save their game as they progress through the levels. Furthermore, due to the popularity of the game, it is easy to find and assign students so that each group has at least one self-proclaimed DOOM expert.

The CS383 DOOM Scenario appeals to active, global, and sensing learners. Active learners enjoy making choices and seeing and often reacting to the results of their choices. Furthermore, they enjoy the cooperative learning environment where they can actively participate in group discussions.
Global learners enjoy learning from the larger perspective where the student must understand how the computer components relate and fit together. Since most of the DOOM questions require the synthesis of multiple learning objectives, the DOOM student response system is an ideal learning component for global students to learn course information. Sensing learners like the real-time three-dimensional environment and the ability to interact with this virtual environment. Finally, regardless of learning style, DOOM adds excitement and variety to the class while requiring a healthy dose of study.

\section{AdAPtive HyPeRMEdia BASED ON LEARNING Styles}

The use of the aforementioned hypermedia tools addresses the needs of approximately $75 \%$ of the students. Anecdotal evidence based on student surveys over three semesters suggests that approximately $25 \%$ of the students remained confused and uncertain at the end of the semester as to how to effectively use the hypermedia material. As a result, an adaptive hypermedia interface was developed to address these students. Common Gateway Interface (CGI) forms were used during the first lesson to determine each student's learning style. These forms were based on an assessment tool developed at North Carolina State University [23]. Students determine their learning style by answering a series of 28 questions. Based on the student's responses, the CGI executable calculates each student's individual learning style, stores this student profile as a file on the WWW server, and associates it with the user's login. There are 720 different, potential learning styles that could be generated from the initial survey.

When the student logs in to begin a lesson, the student is given the option of exploring the course material according to their learning style or without their learning style. If the student chooses to use his or her learning style, a second CGI executable loads the student profile and calculates the effectiveness of the different course media using the heuristics described below. Based on these calculations, the CGI executable dynamically creates an HTML page containing an ordered list of the lesson media elements. These lesson media elements are presented to each student in a sorted list ranked from most to least conducive based on their effectiveness to each student's individual learning style. The students sequentially click on the links to explore the course material according to their personal learning style.

The key to this approach is the determination of what type of media is appropriate for different learning styles. Each hypermedia course element supports one or more learning characteristics. As discussed above, hypermedia courseware addresses the needs of active and reflective learners. Furthermore, since Dr. Solomon did not measure inductive and deductive dimensions in her Inventory of Learning Styles [23], these learning characteristics are removed from consideration in the adaptive hypermedia interface. This leaves the sensing/intuitive, visual/verbal, and sequential/global learning characteristics as the basis for the adaptive hypermedia.

Certain media are inherently appropriate to different learning styles. For example, slideshows, graphics, and digital movies clearly appeal to visual learners while the course hypertext with its text-based, hierarchical, presentation of 


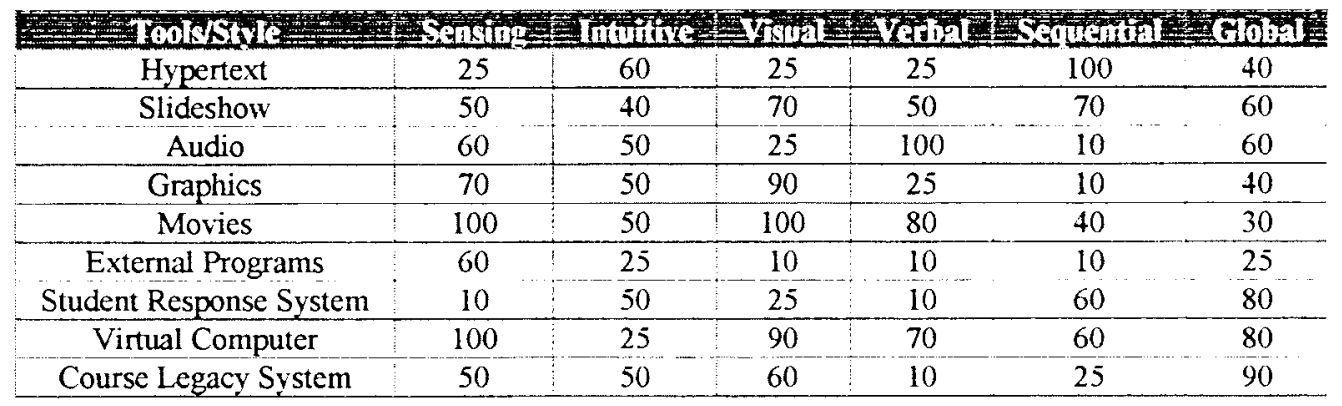

Fig. 3. Media tools and their relationship to learning styles in CS383.

material appeals to verbal, sequential learners. For other media types, media content will determine the degree of support for each learning style. Each course tool was rated on a scale from 0 to 100 to determine the amount of support for each learning style. This rating was combined with the student profile to produce a unique ranking of each media type from the perspective of the student's unique profile. This ranking will differ from course to course depending on the course and media content. Different courses, media, and instructors will result in different tool ratings. The media ranking for CS383 is listed in Fig. 3.

In ranking the course media, the granularity of media ranking can significantly impact the overall effectiveness of the hypermedia interface. If each media element (cpu.gif, intro.wav) can be assigned a learning style ranking, then the adaptive hypermedia system has fine granularity. If each media type (sound files, graphics, hypertext, etc.) receives a ranking, then the adaptive hypermedia system has coarse media granularity. There is tradeoff between the accuracy of the adaptive hypermedia interface and the speed of development of the hypermedia courseware. Adaptive hypermedia systems with fine media granularity accurately match the student's learning styles with the specific media that most directly supports that learning style. However, each media element must be rated in terms of its support of different learning styles. Adaptive hypermedia systems with coarse media granularity can be developed more quickly but are not as accurate.

In determining which approach to pursue, there are two key factors: the size of the resultant hypermedia courseware and the homogeneous nature of the media elements. As the size of the hypermedia system grows, the cost of providing fine tool granularity also grows. In the case of CS383, Computer Systems, the size of the courseware was felt to be too large for a fine granularity adaptive hypermedia interface. Additionally, if the media elements within a media type are homogeneous (i.e., all of the sound files are voice-overs used for the same specific purpose), then little accuracy is gained using a fine granularity adaptive interface. CS383 has fairly homogeneous media elements within the different media types and as such the coarse granularity model provides the better interface.

\section{ASSESSMENT}

The results from a series of informal assessments over the last two years confirm the benefits of addressing different learning styles outside the classroom. Using an end of course survey and a sample population of 100 cadets each semester for the two years, course students were asked which of the hypermedia components was the most conducive to their learning. The result: every semester, every hypermedia component was rated the absolute best by at least one student and every hypermedia component was rated the absolute worst by another. This coorroborates the hypothesis that students learn differently. Students learn different ways through different learning styles. Enhancing student control and flexibility by providing a variety of hypermedia tools that address different learning styles thus enhances student learning.

Learning by using hypermedia is significantly different that learning in a traditional lecture-based course. Students have significantly greater informational resources and as a result, are able to be more active students. Instructors become much more of a facilitator of learning than "the master of all knowledge." Using the end of course surveys, some students report that this shift in responsibility for learning is very unsettling. While the authors believe adaptive hypermedia will address the needs of these students, it remains unproven.

Finally, students appear to only use those hypermedia tools that are available in their rooms. Tools that require the student to use a lab or special equipment are seldom used and poorly rated on average.

Instructors teaching CS383 have noticed a dramatic change in the depth of student knowledge. Students appear to be learning more material at a deeper level. There has been no significant change in the cumulative GPA of the course despite significant changes in the difficulty of the course due to the department philosophy of assigning grades.

It appears that the best students benefit the most from hypermedia courseware and the worst students benefit the least. While the cumulative GPA of the course has remained relatively stable over the last three years, the performance of the best students has substantially increased each semester while the performance of the weakest students has decreased. While several approaches have been implemented to address the needs of these students [24], [25], a formal assessment of the results of this methodology has not been conducted.

It also appears that student requests for additional instruction outside the classroom have been significantly reduced by the hypermedia courseware. By providing a wide range of course informational resources online, students can often answer their questions without asking the instructor. This has been particularly noticeable in questions concerning graded assignments. Using the student response system and the course digital library, students have access to a wide range of submissions 
and questions used on previous course exams and as a result are much less likely to visit the instructor's office or call him/her at home.

It should be noted that the time to develop the course has been substantial. The DOOM scenario required over $200 \mathrm{~h}$ of effort and the time to develop and maintain the complete hypermedia course is nearly $1500 \mathrm{~h}$ over the last three years. Although most of this work has been the result of a single professor and numerous student projects, the development has been incremental based on student comments and instructor insight. Having created the course materials, maintenance of the course requires approximately $100 \mathrm{~h}$ of work at the beginning of each semester as new questions are added to the student response system, the hypertext and slideshows are revised and recompiled, and new media components are added.

\section{CONCLUSION}

As illustrated in Fig. 2, every learning style may be addressed by hypermedia courseware and every learning style is addressed by more than one type of tool. Students have real options as to how and where they learn course material. With these tools, students are empowered to learn using their own unique learning style instead of being forced to learn according to the instructor's view of the material.

Adaptive hypermedia based on student learning styles provides the ability to individually tailor the presentation of course material to each student. The underlying idea of adaptive hypermedia based on learning styles is quite simple: adapt the presentation of course material so that it is most conducive to each student learning the course material. To a certain extent, each student is taking a different course based on what material is most effective for that student. This tailoring allows for efficient and effective student learning in the shortest possible period of time.

Combining these two approaches has the effect of removing from the student's perspective, the impact of the instructor's learning and teaching style and perhaps for the first time, allowing the student to see the material through the clear lenses of the student's own perspective and learning style.

\section{REFERENCES}

[1] C. A. Carver and M. A. Biehler, "Incorporating multimedia and hypertext documents in an undergraduate curriculum," in Proc. 1994 IEEE/ASEE Frontiers in Educ. Conf., Nov. 1994, pp. 87-92.

[2] C. A. Carver and J. E. Gregory, "Networked hypermedia in undergraduate curriculum," in 1995 ED-MEDIA Conf. Educ. Multimedia and Hypermedia, June 1995, pp. 139-144.

[3] C. A. Carver, E. Ressler, and M. A. Biehler. "Low-cost deliverable student response systems," J. Inform. Syst. Educ., Summer, 1995, pp. $73-78$.

[4] C. A. Carver and R. A. Howard, "An assessment of networked multimedia and hypermedia," in Proc. 1995 IEEE/ASEE Frontiers in Educ. Conf., Nov. 1995, pp. 2c5.17-2c5.21.

[5] I. Beumont and P. Brusilousky, "Adaptive educational hypermedia," in 1995 ED-MEDIA Conf. Educ. Multimedia and Hypermedia, June 1995, pp. 93-98.

[6] C. Boyle and A. O. Encarnacion, "MetaDoc: An adaptive hypertext reading system," User Modeling and User-Adapted Interaction, vol. 4 pp. 1-19, 1994.

[7] P. Brusilousky and L. Pesin, "ISIS-tutor: An adaptive hypertext learning environment," Japanese-CIS Symp. Knowledge-Based Software Eng., May 1994, pp. 83-87.
[8] I. Beumont, "User modeling in the interactive anatomy tutoring system," User Modeling and User-Adapted Interaction, vol. 4, pp. 21-45, 1994.

[9] P. Brusilousky, "Intelligent tutor, environment, and manual for introductory programming," Educ. Training Technol. Int., vol. 29, no. 1, pp. 26-341, 1992.

[10] Fischer, G. Mastaglio, T. B. Reeves, and J. Rieman, "Minimalis explanations in knowledge-based systems," in 23rd Annu. Hawaii Int. Conf. Syst. Sci., Jan. 1990, pp. 309-317.

[11] A. Hekmatpour, "An adaptive presentation model for hypermedia in formation systems," J. Educ. Multimedia and Hypermedia, vol. 4, no. 2/3, pp. 211-238.

[12] R. M. Felder and L. K. Silverman, "Learning and teaching styles in engineering education,” Eng. Educ., vol. 78, no. 7, pp. 674-681, Apr. 1988.

[13] R. M. Felder and L. Baker-Ward, "How engineering students learn, how engineering professors teach, and what goes wrong in the process," in Proc. 1990 Frontiers in Educ. Conf., 1990, pp. 82-84.

[14] R. M. Felder, "Reaching the second tier-learning and teaching styles in college science education," J. College Sci. Teaching, vol. 23, no. 5, pp. 286-290, Mar./Apr. 1993

[15] S. Montgomery, "Addressing diverse learning styles in a large classroom," in 1995 ASEE Nat. Conf. Proc., June 1995, pp. 344-349.

[16] S. Montgomery and H. S. Fogler. "Selecting computer-aided instructional software," J. Eng. Educ., vol. 85, no. 1, pp. 53-60.

[17] D. A. Kolb. Experimental Learning: Experience as the Source of Learning and Development. Englewood Cliffs, NJ: Prentice-Hall.

[18] J. N. Harb, S. O. Durrant, and R. E. Terry, "Use of the kolb learning cycle and the 4MAT system in engineering education," J. Eng. Educ., vol. 82, no. 2, pp. 70-77.

[19] M. H. McCaulley, E. S. Godleski, C. F. Yokomoto, L. Harrisberger, and E. D. Sloan, "Applications of psychological type in engineering education," J. Eng. Educ., Feb. 1983, pp. 394-400.

[20] H. L. Capron and J. D. Perron, Computers \& Information Systems, 3rd Edition. Redwood City, CA: Cummings, 1993.

[21] T. Shelley, G. Cashman, W. Waggoner, and T. Waggoner, Using Computers: A Gateway to Information. Denver, CO: Boyd and Fraser, 1995.

[22] B. S. Bloom, Taxonomy of Educational Objectives: The Classification of Education Goals. New York: David McKay.

[23] B. S. Solomon, Inventory of Learning Styles, North Carolina State Univ., 1992.

[24] C. A. Carver, R. A. Howard, and W. D. Lane. "A methodology for active, student-controlled learning: Motivating our weakest students," in Proc. 27th Tech. Symp. Comput. Sci. Educ., Feb. 1996, pp. 195-199.

[25] _ _ "Active student controlled learning-Reaching the weakest students," Liberal Educ., vol. 82, no. 3, pp. 24-29, 1996.

Curtis A. Carver Jr. received the MS degreee in computer science from Texas A\&M University, College Station, in 1993. He is currently a doctoral student at Texas A\&M University preparing to return to the U.S. Military Academy.

He was previously an Assistant Professor in the Department of Electrical Engineering and Computer Science. His research interests include distributed multimedia, hypermedia, object-oriented systems, and network security.

Richard Howard received the M.S. degreee in computer science from the Naval Postgraduate School in 1990.

He was previously an Assistant Professor in the Department of Electrical Engineering and Computer Science. He is currently the Director of Network Operations for the U.S. Military Academy. His research interests include network operating systems, network security, and computer graphics.

William Lane received the Ph.D. degreee in electrical engineering from the Georgia Institute of Technology, Atlanta, in 1988.

$\mathrm{He}$ is an Associate Professor and Director of the Information Technology Center of Excellence in the Department of Electrical Engineering and Computer Science at the U.S. Military Academy. His research interests include spread spectrum systems, low probability intercept, and multimedia education. 